\title{
Development of an innovative composite mullion
}

\author{
S. Jiao, S. Gunalan \& B. P. Gilbert \\ Griffith University, Gold Coast, QLD, Australia \\ B. Baleshan \\ G. James Glass \& Aluminium Pty. Ltd., Brisbane, QLD, Australia \\ H. Bailleres \\ Department of Agriculture and Fisheries, Brisbane, QLD, Australia
}

\begin{abstract}
The façade, as the exterior cladding of a building, is an essential component. The vertical member, named mullion, is the dominant wind load-bearing structural member in this façade system. The conventional aluminium frame is weak in thermal performance. On the other hand, timber frames are preferred by architects due to their aesthetic appearance and sustainability. Therefore, an innovative composite mullion was developed in this study using aluminium and timber to achieve the best features of both materials. An experimental study was also conducted to verify the structural performance of the composite mullion. The test results showed that the section moment capacities of the composite mullions are greater than the traditional aluminium mullions.
\end{abstract}

\section{INTRODUCTION}

Extruded aluminium façade frames have been widely used since the 1970 s due to their light weight, high corrosion resistance and being able to be easily extruded. However, the conventional aluminium façade frame is weak in thermal performance. In addition to energy efficiency, architects expect the modern frame to have some other important features including aesthetics and sustainability. Recently, composite mullions made of aluminium and sawn timber are proposed to obtain the better of timber and aluminium. However, the problem with this concept is that there is no coupling mechanism for efficient on-site installation. This paper presents a new composite mullion, which is durable, energy efficient, aesthetically pleasing and sustainable, while having the coupling mechanism for effective installation in the wide range of curtain wall and window wall applications. Huang (2014) investigated a composite façade mullion with a thermal break and tested its connection shear capacity and section moment capacity. Kesawan et al. (2018) conducted a series of experimental tests to investigate the section moment capacity of aluminium mullions. This paper presents the development of this innovative mullion using experimental studies.

\section{EXPERIMENTAL STUDIES}

\subsection{Connection tests}

For this composite structural component, one of the concerns is the strength of the joint between aluminium and timber. A total of 12 connection samples subjected to shear loading were tested using the Material Testing System (MTS) $500 \mathrm{kN}$ universal testing machine in Griffith University Engineering Laboratory (Figure 1) to investigate this behaviour. Four different types of connections with three repetitive tests were performed. The samples were labelled to indicate the connection type (screw or glue), the diameter of the screw ( 3 or $5 \mathrm{~mm}$ ) and the spacing of screws $(150 \mathrm{~mm}$ or $75 \mathrm{~mm}$ ). For example, ' $\mathrm{S}-5-150$ ' is designated for a screw connection sample with 5-mm screws in $150 \mathrm{~mm}$ spacing.

Table 1. Connection test results

\begin{tabular}{lll}
\hline Section & Failure mode & Capacity \\
\cline { 3 - 3 } & & N/mm \\
\hline S-3-150 & Screw bending & 19.2 \\
S-3-75 & Screw bending & 36.5 \\
S-5-150 & Plywood yielding & 39.3 \\
Glue & Rolling shear & 71.7 \\
\hline
\end{tabular}

Two nominally identical samples were fully restrained using T-shaped steel plates and steel packing plates. Table 1 shows the average shear capacities of these four connections. The glue connection is proposed for the development of the composite 
mullion due to increased strength, ease of manufacturing and aesthetic reasons.

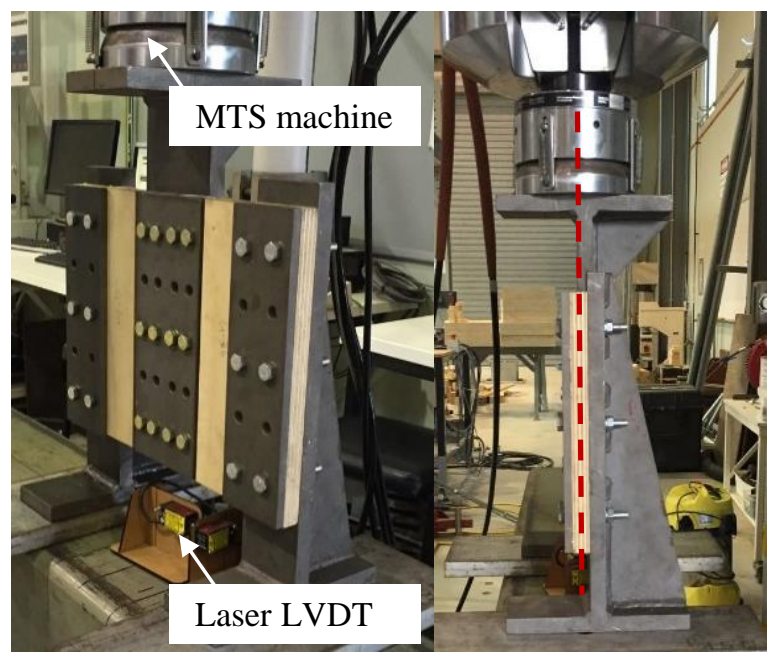

Figure 1. Connection test set-up.

\subsection{Four-point bending tests}

The test specimen comprises four parts: an aluminium exterior extrusion, a plywood web, a plywood flange and an aluminium flange as shown in Figure 2 . The composite mullions with two different thicknesses were tested. Furthermore, the original aluminium mullions were also considered. Table 2 shows the test specimen details. Seven tests were performed including one repetitive test. "AL" and "CO" indicate the aluminium and composite mullion, respectively. " $M$ " and " $F$ " indicate male and female sections respectively, the number " 1 " and " 2 " indicate the thin and thick plywood, and the letter " $\mathrm{R}$ " indicates the repetitive test.

A four-point bending test set-up was used to obtain the section moment capacity as shown in Figure 2. The mullions were fully back-to-back restrained with T-shaped steel. A steel half roller and a steel roller were placed under the T-shaped plates at the support points and two steel rollers were placed on the T-shaped plates at the loading points. The load was applied through a spreader beam pinned with a steel plate which was gripped by the cross-head of the MTS machine.

Table 2 summarises the section moment capacities from the tests. The section moment capacities of the composite mullions are greater than the aluminium mullions except for the female thin composite mullion where it was equal. Local buckling was observed at the mid-span during the aluminium mullion tests. However, the composite mullions failed in compressive yielding of the timber and buckling of aluminium.

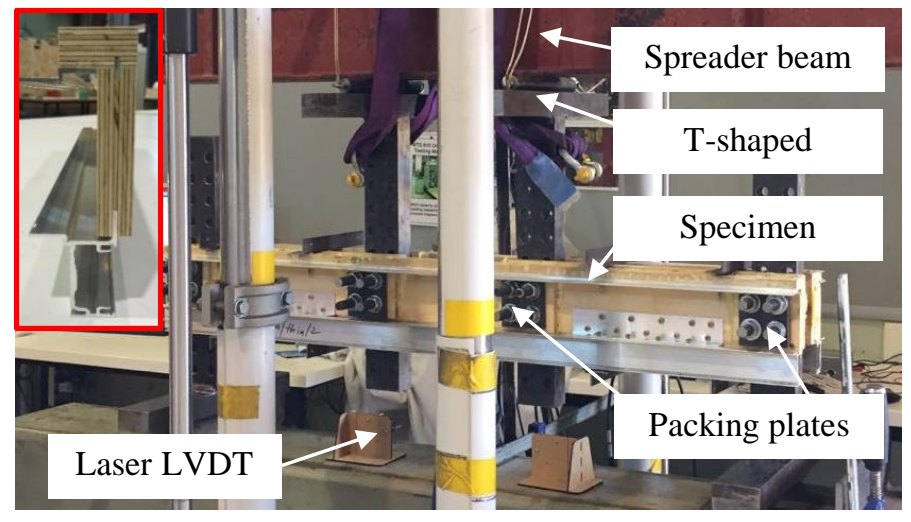

Figure 2. Four-point bending test set-up.

Table 2. Failure modes and test results

\begin{tabular}{llll}
\hline Section & Failure Mode & Capacity & \multirow{2}{CO}{$\begin{array}{l}\mathrm{CO} / \mathrm{AL} \\
\text { ratio }\end{array}$} \\
\cline { 3 - 3 } & & $\mathrm{kNm}$ & - \\
AL-M & Local buckling & 5.04 & - \\
AL-F & Local buckling & 4.92 & -13 \\
CO-M-1 & Yielding and buckling & 5.68 & 1.13 \\
CO-M-2 & Yielding and buckling & 6.92 & 1.37 \\
CO-F-1 & Yielding and buckling & 4.97 & 1.01 \\
CO-F-1-R & Yielding and buckling & 4.87 & 0.99 \\
CO-F-2 & Yielding and buckling & 6.18 & 1.26 \\
\hline
\end{tabular}

\section{CONCLUSION}

This paper has presented the details of the development and experimental investigation of an innovative composite mullion which is structurally strong, energy efficient, aesthetically pleasing and sustainable with a coupling mechanism. Twelve connection specimens were tested to ensure the composite actions and to determine the optimum connection for the composite mullion. The adhesive bond forms the composite connection with the best strength and appearance. Four composite mullions and two aluminium mullions were tested using the four-point bending test set-up. The test set-up is presented in detail in this paper. The results showed that the innovative composite mullions have greater section moment capacities than the original aluminium mullions.

\section{ACKNOWLEDGEMENT}

The authors are grateful to the School of Engineering and Built Environment of Griffith University for providing the test facilities and financial support.

\section{REFERENCES}

Huang, S. 2014. Investigation of composite façade mullions (Doctoral dissertation).

Kesawan, S., Mahendran, M. and Baleshan, B., 2018. Section moment capacity tests of complex-shaped aluminium mullions. Thin-Walled Structures, 131, pp.855-868. 